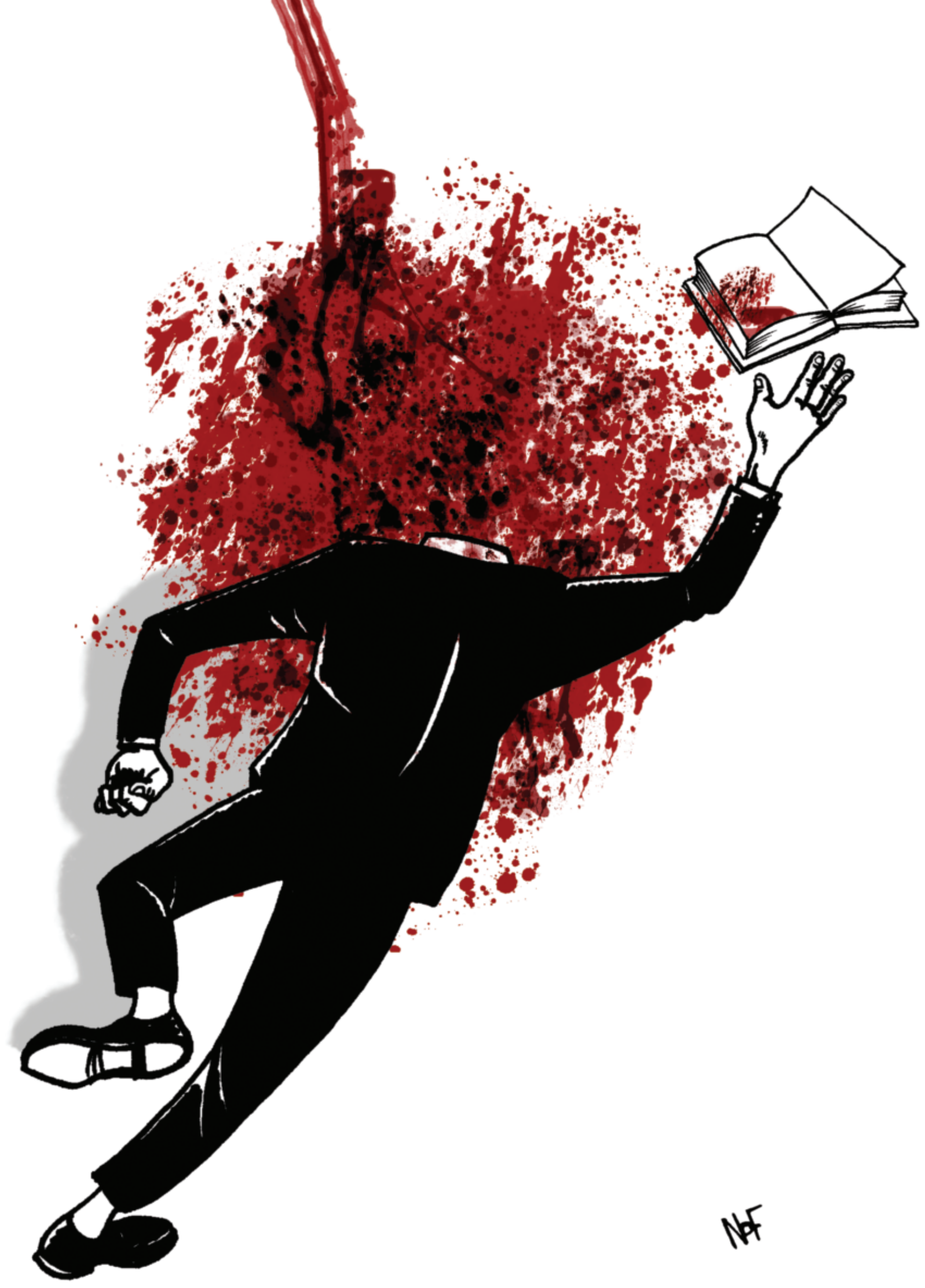




\section{Ciencia y arte}

\section{Abdón Ubidia*}

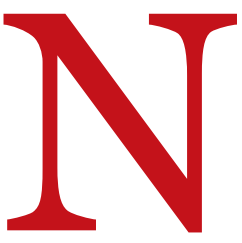

o vivimos el Renacimiento. Leonardo y Miguel Ángel ya no son posibles. En principio, porque ya nadie puede saber todo. El conocimiento acumulado es hoy tan grande que la figura del especialista rige el mundo. Pero nadie puede ser especialista en todo. Esa es una realidad palmaria. Además, hay una imposición propia de las postrimerías de la modernidad, o propia del capitalismo tardío, que es lo mismo: la separación interesada del mundo de las ciencias humanistas y el de las ciencias exactas.

* Abdón Ubidia, Narrador, ensayista, antólogo y crítico literario. En la década de los sesenta fue parte del movimiento contestatario Tzántzico, posteriormente colaboró con la revista La bufanda del Sol editada en Quito; en los ochentas dirigió la revista cultural Palabra Suelta. Entre su obra consta: Novela: Ciudad de invierno (Quito, 1984); Sueño de lobos -Premio "José Mejía Lequerica"- (Quito, 1986). Cuento: Bajo el mismo extraño cielo (Bogotá, 1979); Divertinventos (Quito, 1989); El palacio de los espejos (Quito, 1996). Teatro: Adiós siglo XX (Quito, 1992). Ensayo: El cuento popular (Quito, 1977); La poesía popular ecuatoriana (Quito, 1982); Referentes (Quito, 2000), entre muchas otras. 
Lo dijo C.P. Snow en su libro Las dos culturas, en 1951. Pero esa separación no es casual. Tiene una sombra. Es útil y funcional al mundo actual. A su ordenamiento y control obligatorio. La economía, tanto en la esfera de la producción como de la distribución de los ingresos, está gobernada por especialistas sumidos en el saber científico y tecnológico; muchos de ellos logran progresos indudables en la medicina de hoy: la genética y la neurología, por ejemplo. $\mathrm{O}$ en la exploración de las nanotecnologías, con el consiguiente invento de nuevos materiales. Y está, en primer plano por cierto, la aparición y perfeccionamiento del orbe informático y la globalización de las comunicaciones gracias al Internet. Todo eso redunda en el aprovechamiento máximo del tiempo humano. Todo se ha vuelto más veloz y acelerado. $Y$ esa aceleración no tiene, al parecer, ningún límite. Sin embargo, de seguro, muy pocos científicos y técnicos, puestos al servicio de las grandes corporaciones multinacionales, agobiados por el estrés que les imponen sus trabajos, se preguntarán qué sentido tiene ese gran ahorro del tiempo humano que han logrado: el porqué de esa rapidez, la razón de un mundo agobiado por la depredación de los recursos naturales, que ellos, quizá inocentemente -tal es su alienación-, han causado. Se vive más y más de prisa pero, en términos humanos, la bondad de la vida no es mejor. Y el peligro de la extinción de nuestra especie es más real que nunca. Y no solo por la destrucción de nuestro hábitat (el calentamiento global se debe, en buena parte, a los abusos tecnológicos). También los "progresos" de la industria bélica están hechos para matar personas concretas de forma más eficiente. La mitad del presupuesto de los Estados Unidos está dedicado a dicha industria. Con lo cual, la finalidad misma del progreso y el desarrollo muestran bien su rostro feroz: no están al servicio de la liberación humana, de su acceso a la justicia distributiva ni de la concordia entre naciones y grupos. Están al servicio de otra cosa muy distinta: el capital. De su acumulación vertiginosa, depredadora e inequitativa. Un tercio de la población mundial vive con un dólar al día. Quiere decir, que quienes detentan el poder científico y tecnológico lo hacen en nombre de su propio interés capitalista. Se calcula que la mayor parte de la riqueza del mundo está en poder de 200 familias. En términos generales, los grandes científicos de hoy, enfrascados en sus trabajos, inmersos en ellos, no se plantean siquiera su responsabilidad ante ese orden de cosas que tan obsesivamente ayudan a construir. Porque confían en un progreso y un desarrollo infinitos como finalidades únicas. La prueba está en los abusos de la industria farmacéutica, La industria criminal, como la llamó John Le Carré, y cuyos abusos han sido denunciados en muchos libros, por ejemplo, Los crímenes de las grandes farmacéuticas, escrito por la monja Teresa Forcades i Vila.

Y basta leer libros como La doctrina del shock, de Naomi Klein, para enterarnos de que los científicos que trabajaron en el Tamiflu, la droga inútil, que fuera el gran negocio de Donald Rumsfel (el ex secretario de Defensa de Bush, quien usó una estrategia de guerra para venderla, primero como medicina contra la gripe aviar y, luego, para la H1N1), no se preocuparon nunca de que trabajaban para un gran negocio y no para el alivio del dolor humano. Qué decir de quienes crearon la Talidomida o los medicamentos que tienen que ser retirados del mercado por sus efectos adversos, entre ellos, buena parte de los anti-inflamatorios. Qué decir de aquellos que trabajan en la construcción de inverosímiles armas -químicas o nucleares- de destrucción masiva. Ellos, enajenados al crecimiento del capital, han perdido, a la par, la noción del límite y de los objetivos concretos de la ciencia.

Ahora bien, ¿̇cómo hemos llegado a esta situación? La respuesta parece encontrarse en lo que anotaba Snow: la separación obligatoria de las dos culturas: la científica y la humanista. Salvo los grandes casos de excepción: Einstein, en primer lugar, el científico y 
el tecnólogo no se interesan ni por la filosofía ni por la literatura ni el arte. Es decir: ni por la crítica del devenir humano, ni por lo que Adorno llamaba el arte como lenguaje del dolor humano. Con buenos sueldos, el objetivo final y posible de la ciencia y la tecnología, como liberadoras del trabajo y del tiempo, no es una prioridad.

Hay excepciones, por cierto, sobre todo en el campo de la medicina: inventores de vacunas que, como el doctor Patarroyo, no patentan sus inventos, es decir, renuncian a comercializarlos, a volverlos capital productivo.

En el otro extremo están las ciencias y artes de los humanistas. Pocos de ellos tienen acceso a la información tecnológica. Y hablan lenguajes adocenados, controlados por Academias que, en el campo específico del arte contemporáneo, promueven una práctica distorsionada que, en lugar de exaltar la figura del artista, tiende a matarla. La prueba es, ahora, esto que han llamado arte neoconceptual. Un arte programado para los curadores, convertidos en "artistas de artistas", nuevos comisarios de lo que debe ser, y no para los artistas que se han realizado en una larga paciencia, que junta el gusto, el don, la pasión y el oficio en obras que, muchas veces, cuestionan el mundo actual.

Pero el caso que más nos interesa ocurre en el ámbito literario: casi por definición el lugar geométrico del humanismo. La renuencia de los escritores y artistas a enterarse del saber de las ciencias exactas y, por extensión, de los avances muy concretos y reales de la física y la química actuales (la cuántica, por ejemplo), pasto también, por desgracia, de tantos charlatanes, pero fuente inagotable de incertidumbres que hacen tambalear nuestro saber epistemológico más profundo: partículas que pueden ocupar dos lugares a un tiempo; conexiones que las relacionan más allá de las distancias; propiedades, antes impensables, que ya son y serán los soportes de las nanotecnologías, por ejemplo. O descubrimientos, en la macrofísica, que hacen anticipar a algunos astrónomos la existencia, ya no de un universo mayor al que jamás previmos, sino la existencia de uno o infinitos "multiversos”, entre los cuales, el nuestro solo sería uno más.

La pregunta es: ¿Cómo controlar el cada vez mayor conocimiento científico para que, como el monstruo de Frankestein, no se nos escape y termine por destruirnos? La respuesta, quizá, podamos encontrarla en el gesto de volver a la unidad del saber humano, a la unidad del saber científico y el humanista. Volviendo a lo que el gran Bachelard decía, en su Sicoanálisis del fuego y del investigador, puesto que, en lo hondo de sus corazones, aunque escondidas, y a veces inconfesables, palpitan las mismas inquietudes profundamente humanas. Así, quizá los puentes entre el arte y la ciencia serían más fáciles de restablecer. 